\title{
Analyze a Better Knowledge Management Tool
}

\author{
Faz Mohammad \\ M.Tech Scholar (CSE) \\ Ajay Kumar Garg Engineering College
}

\author{
Archana Bhardwaj \\ M.Tech Scholar (CSE) \\ Ajay Kumar Garg Engineering College
}

\begin{abstract}
Now a day there are huge amount of data are available at different repositories. Data may be individual or inter-connected. A management strategy is required, which can arrange data and can fetch knowledge from a huge amount of data. To fetch the important information from available huge amount of data is a big challenge. Here we are discussing some knowledge management tools which extract and manage the important information according to need of the user.A data mining technique can arrange and fetch knowledge but here we are discussing the tools which arrange, identify, represent, create, adopt and distribute the knowledge and experience. These tools may directly or indirectly interact with decision making for an organization or individual. In this paper we are discussing about the knowledge management tool which are available online, offline and some tools by which an individual can transfer his knowledge from one person to other persons.
\end{abstract}

\section{Keywords}

Knowledge Management, Knowledge Management Tools, knowledge extraction, strategic decision making, Lotus, Tinder box .

\section{INTRODUCTION}

Knowledge management (KM) is an approach used to identify, represent, create, distribute, and enable adoption of insights and experiences in an organization. The knowledge consists of such insights and experiences, which can be personified in individuals or can be implanted in organizations for application purpose or management [9]. There are some traditional approach for knowledge management to improve the flow of knowledge in practices, like within a group, an organization, by recording and making available what its members know. Knowledge is of two types' tacit knowledge and explicit knowledge. Tacit knowledge is difficult to transfer to another person by means of writing it down or verbalizing it and explicit knowledge can be articulated, codified, and stored in certain media, it can be readily transmitted to other (Peterson 2010). There are various knowledge management tool exists to manage the tacit knowledge [11]. Novel approach to knowledge management is to improve the productivity, reliability and quality of an organization. Knowledge management is necessary for an organization to provide knowledge to the right person at the right time with right meaning. In this paper various $\mathrm{KM}$ tools are discussed according to their requirement and specification.

\section{KNOWLEDGE MANAGEMENT TOOLS}

Knowledge management tools (KM tools) are a subset of enterprise content management tool, which incorporates varieties of software that specializes in the way information, is piled up, stored and access (Holland and Dawson 2010). The concept of knowledge management is based on a range of practices used by an individual, a business, or a large corporation to identify, creates, represent and redistribute information for a range of purposes. Software that enables an information practice or range of practices at any part of the process of information management can be seemed to be called an information management tool [11] A subset of information management software that emphasizes on an approach to build knowledge out of information that is managed or contained is often called knowledge management software (Henninger 1997). A well defined process for knowledge management can be managed to knowledge manually but in case of automation knowledge management tool decides that at which time which type of information should be passed for a particular query, so an artificial intelligence program should be attached with knowledge management process and after attaching artificial intelligence program it will become a knowledge management tool (Clemente 2005). There are many types of knowledge management tools available online, offline and in real life.

In this paper we have defined 11 online, offline and real life knowledge management tools. These tools are defined with its specification and purpose. A particular tool may be used for defined specific purpose.

This paper is organized in four sections. Section I gives an introduction about our study. In section II we have defined 11 knowledge management tools and its specifications. A comparative analysis is represented in section III and section IV gives an overall conclusion about this paper and one can get an advantage to fine better knowledge management tool.

\section{LITERATURE REVIEW}

After literature review we get that there are so many tools available in day to day life. Mostly used and important tools are defined in this section of our paper.

\section{GROUPWARE SYSTEMS}

This tool is used to collaborate with the people of an organization which can be used in communication, conferencing and management. Lotus Notes is a well known groupware system. The lotus is a knowledge management tool, developed by Lotus Development Corp. and IBM in September 2000 (IBM 200). Lotus believes that there are five core technologies that underpin Knowledge Management: Business Intelligence, Collaboration, Knowledge Transfer, Knowledge Discovery, and Expertise Location. Lotus and IBM has identified People, Places 
\& Things as the three essential ingredients of an effective knowledge management infrastructure (IBM 1998). In groupware system workers can work together and can share their knowledge but this approach will not be effective without any top executive support.

\section{INTRANET AND EXTRANET}

The intranet is also a knowledge management tool for smaller size organization with similar functionality. With the help of intranet, knowledge can be managed in term of flow (downloading and uploading) of knowledge, store knowledge on the server, updating of knowledge, response according to the query. But intranet can be used for a limited purpose and limited area. With the help of intranet, knowledge can be shared for news, navigation, key information, community and culture, internal marketing, collaboration (Schuft, Doray and Coroson 2007 ). In a similar way extranet is used to control access of organizational information and knowledge resources between or among different organizations.

\section{DATA WAREHOUSE, DATA MINING AND OLAP}

Data warehouse are a central repository of data which is created by integrating more than one database. A data warehouse contains a link of historical and current knowledge by which a strategic decision can be made by higher authority. With the help of data warehousing tools, interrelated knowledge can be flown from different knowledge sources [11]. A data warehouse is developed by integrating more than one knowledge resources and extracted knowledge is transferred to the appropriate workstation as shown in Fig 1. [12] All the data repositories are connected to ETL (extraction, transformation loading) module to arrange all data and stored it in the data warehouse and send it to the output penal according to the query.

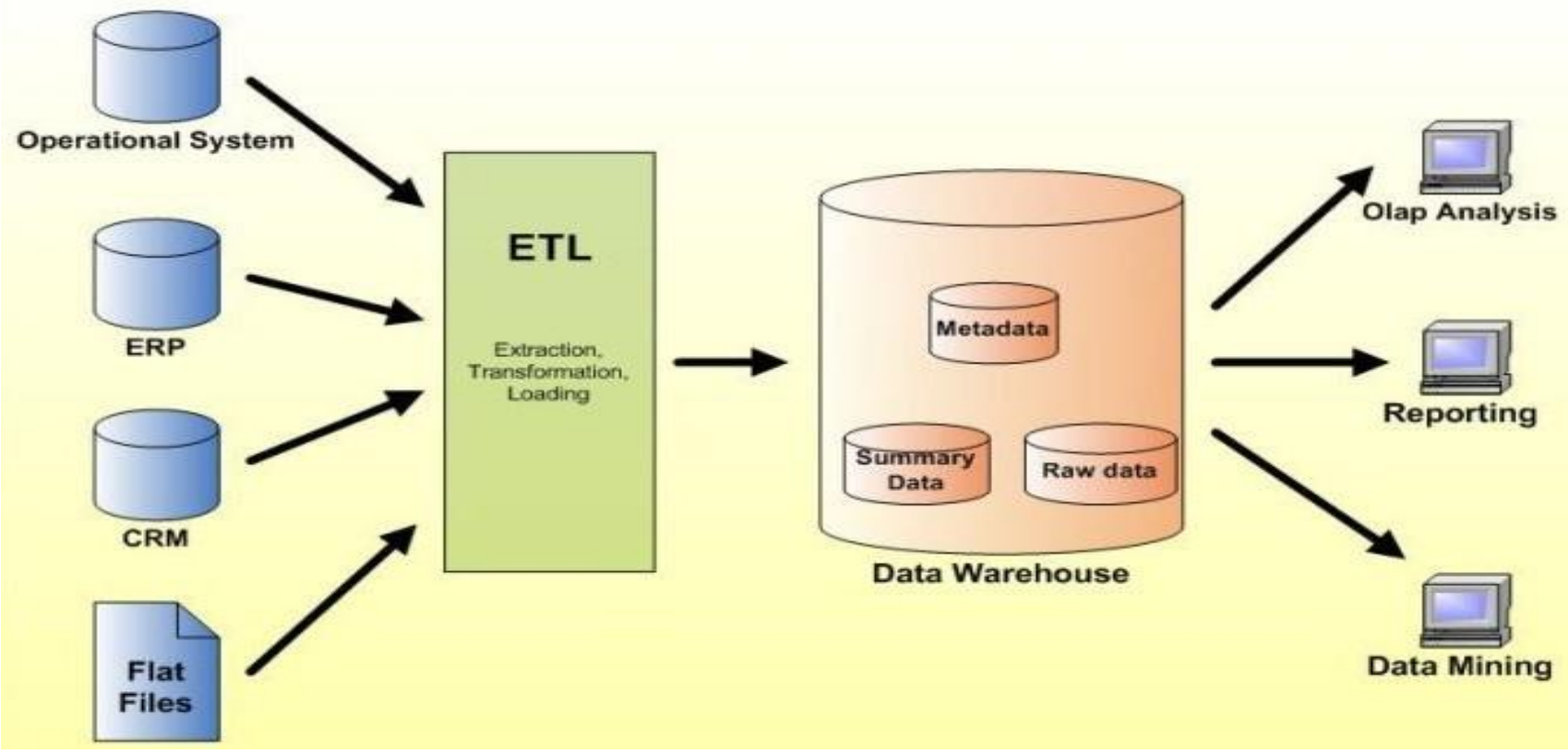

Figure 1[12]: Flow of knowledge in Data warehouse.

OLAP (OnLine Analytical Processing) is a knowledge management tool to extract knowledge in multidimensional view. Manager of the organization can make good decisions by taking more than one parameter at a time using OLAP tool. It reduces the large amount of knowledge into formulas that capture the answer to the query.

\section{CONTENT MANAGEMENT SYSTEMS}

The content management system is a tool to create, manage, and distribute the knowledge available on intranet, internet and extranet. Content management provides an infrastructure for managing the knowledge according to query. A content management system may provide some functions - templates for publishing, tag content with meta-data, editable content, collaborative work on content and workflow management. At the time of selection of a content management system, some factors should be considered e.g. technology, ease to use, total cost of ownership, cross platform support and scalability, web presence management and solution deployment. Tinderbox is an application tool for content management system. Tinderbox is a personal content management system and personal knowledge base. It is developed for Mac OS and Mac OS X by Eastgate
Data mining is another tool to extract knowledge from the available large amount of data [11]. Data mining process is the set of sub-processes to extract the knowledge from a large amount of data. The sub processes used for data mining to do business understanding, data preparation, modeling, evaluation and deployment.

Systems. It stores and organizes notes, plans, and ideas and helps in analyzing and understanding them. The latest version of tinderbox is 5.9.3 and released on August 2011. Tinderbox is a powerful but a personal content assistant tool that shares your notes through the cloud and on the web and builds relationships, by arranging notes, organizing them with shapes, color and linking them. Tinderbox records ideas quickly and keep them where it is needed again. It is a content management tool for displays maps, timelines, charts, outlines, and can have many views open at once and it also has prototypes, saving effort time and keeping work organized. Tinderbox agents scan notes continuously and present required note (Ranjan and Khalil 2007). Agents can look for tasks that are overdue, or notes that needed to complete, or topics of interest and can automatically update notes from the internet. It is fast and can handle thousands of 
notes with ease. Tinderbox files are XML and can create HTML, XML, RSS, OPML, and more. Application notes and case studies explore uses of Tinderbox from Forensic Psychiatry to writing musical comedy. The tool works the way the user wants, and adapts gracefully as user needs.

\section{DOCUMENT MANAGEMENT SYSTEMS}

Document management system is used to publish, store, indexing, and retrieval of knowledge in the form of documents. Document management systems provide an infrastructure for knowledge management in the form of a document which can be transferred, stored, manipulated at any time and can be used to extract knowledge for a strategic decision (Ranjan and Khali 2007). It provides some functions like capturing of knowledge, classification of knowledge using metadata, indexing of knowledge, searching and retrieval, versioning of document, administration and security of documents.

\section{SEMANTIC NETWORK}

Semantic net is a tool to manage the knowledge in the form of nodes and arcs [10]. Nodes represent entities and arcs represent relationship among the nodes. Semantic net may be directed or undirected and semantic net should be used when the concepts are well clear and are related to each other.

\section{CROSS-FUNCTIONAL PROJECT TEAM MANAGEMENT}

In any organization if a team is working on a project of different functions then knowledge can be flown from one member to another member of different function in a team. Most projects require a wide variety of skills with the help of which project can be completed easily (Berler, Pavlopoulos and Koutsouris 2005). Leadership is essential to manage crossfunctional project teams and knowledge management easily.

\section{VISUAL UNDERSTANDING ENVIRONMENT (VUE)}

Visual understanding environment is an open source tool launched in June 2005. VUE project was focused on creating flexible tools for managing and integrating digital resources in

Table 1. Comparative analysis: knowledge management tools

\section{KNOWLEDGE MANAGEMENT TRAINING}

Education and consultancy are two categories of knowledge management training. Knowledge management training is accomplished by education in different ways e.g. online and offline courses, university degrees, KM workshops \& conferences, knowledge management books and journals and knowledge management games (Ranjan and Khalil 2007). Knowledge management training can also be performed by consultants to pass the tactical knowledge to the employees of an organization.

\section{STORYTELLING}

Storytelling is a very old technique to pass the knowledge and wisdom from one person to another person. In storytelling technique, knowledge and wisdom are transferred in the form of messages. For an organizational culture, storytelling is used to shape vision and to shape identity (Holland and Dawson 2010) The role of storytelling as follows e.g.- shared norms and values, develop trust and commitment, share tactic knowledge, facilitate on learning and generate emotional connection. Storytelling technique focuses on positive thinks and having a hero.

\section{MENTORING}

Mentoring is a way of passing down tactic knowledge from an expert to another aspiring expert. Mentoring is a technique to practice under an expert guide (Holland and Dawson 2010). Mentoring is done by a well educated and social person. Mentor should have some characteristics e.g. personal expertise, familiarity with the organization, desire to teach, ability to motivate, ability to allow for personal development of the mental, commitment, skilled communicator, ability to remain professional, self-awareness and self-critical and ability to foster trust.

support of teaching, learning and research (Peterson 2007). VUE provides a flexible visual environment for structuring, presenting, and sharing digital information.

\section{COMPARATIVE ANALYSIS}

\begin{tabular}{|l|l|l|l|l|}
\hline S. No. & Knowledge Management Tools & Purpose & Specification & Limitation \\
\hline 1 & Groupware System & $\begin{array}{l}\text { Collaborate with the people in } \\
\text { organization }\end{array}$ & $\begin{array}{l}\text { Communication, } \\
\text { conference, } \\
\text { management }\end{array}$ & $\begin{array}{l}\text { Not effective without } \\
\text { any executive support }\end{array}$ \\
\hline 2 & Intranet and Extranet & $\begin{array}{l}\text { Information passing in small } \\
\text { size organization with similar } \\
\text { functionality }\end{array}$ & $\begin{array}{l}\text { News, navigation key, } \\
\text { community and culture, } \\
\text { internet marketing }\end{array}$ & Not for global use \\
\hline 3 & $\begin{array}{l}\text { Data Warehouse, Data Mining and } \\
\text { OLAP }\end{array}$ & Strategic decision making & $\begin{array}{l}\text { Integrate knowledge } \\
\text { from different resources }\end{array}$ & $\begin{array}{l}\text { Large no. of steps are } \\
\text { required }\end{array}$ \\
\hline 5 & Content Management System & $\begin{array}{l}\text { Knowledge frame according } \\
\text { to query }\end{array}$ & $\begin{array}{l}\text { Templates, tag content, } \\
\text { metadata, work flow } \\
\text { management }\end{array}$ & $\begin{array}{l}\text { Don't allow } \\
\text { indentation, not provide } \\
\text { bulleting and } \\
\text { numbering }\end{array}$ \\
\hline
\end{tabular}




\begin{tabular}{|l|l|l|l|l|}
\hline 6 & Semetic Net & Categories concept & $\begin{array}{l}\text { Knowledge } \\
\text { management in term of } \\
\text { nodes and arcs }\end{array}$ & $\begin{array}{l}\text { Concepts should be } \\
\text { well cleared }\end{array}$ \\
\hline 7 & $\begin{array}{l}\text { Cross Functional Project Team } \\
\text { Management }\end{array}$ & Integrates different skills & $\begin{array}{l}\text { Make a project of } \\
\text { different function }\end{array}$ & $\begin{array}{l}\text { Leadership is required } \\
\text { to manage }\end{array}$ \\
\hline 8 & Knowledge Management Training & Transfer tacit knowledge & $\begin{array}{l}\text { Education in different } \\
\text { ways }\end{array}$ & Third party is required \\
\hline 9 & Storytelling & $\begin{array}{l}\text { Knowledge and wisdom } \\
\text { transfer in form of messages }\end{array}$ & $\begin{array}{l}\text { Generates emotions, } \\
\text { connection and +ve } \\
\text { thinks }\end{array}$ & $\begin{array}{l}\text { Communication } \\
\text { medium required }\end{array}$ \\
\hline 10 & Mentoring & $\begin{array}{l}\text { Motivation and personal } \\
\text { development }\end{array}$ & $\begin{array}{l}\text { Passing down tacit } \\
\text { knowledge }\end{array}$ & $\begin{array}{l}\text { Desire to teach and } \\
\text { desire to learn required }\end{array}$ \\
\hline 11 & Visual Understanding Environment & $\begin{array}{l}\text { Integrates digital resources } \\
\text { research }\end{array}$ & $\begin{array}{l}\text { Applied to digital } \\
\text { information only }\end{array}$ \\
\hline
\end{tabular}

Various knowledge management tools are compared according to its purpose, specification and limitation.

\section{IV.CONCLUSION}

This paper can help to Industry persons and researchers to find a best knowledge management tool. After referring research papers and surveys we did a comparative analysis of knowledge management tools. Comparative analysis is defined in table 1. We can further refine the requirement of tool and tool's features. Knowledge management tools are analyzed according to its purpose and specifications. One can compare and select a best tool according to their requirements.

\section{V.REFERENCES}

[1] Bernadette E. Clemente, "personal knowledge management - Mapping the Course Marketing the Trail", IEEE computer society, November, December 2005, $1520-9202 / 05$.

[2] Alexender Berler, Sotiris Pavlopoulos and Dimitris Koutsouris," using key performance indicators as knowledge management tool at a regional health care authority level, IEEE transaction on Information Technology in Bio-Medicine Vol. 9 No. 2, jun 2005.

[3] Suzi Holland and Ray Dawson, " classification and selection of tools for quality knowledge management," springer science+business media, Software Qual J (2011) 19:393-409-2010.
[4] Scott Henninger, "case-based knowledge management tool for software development," Automated Software Engineering 4, 319-340 (1997).

[5] David Schuff, Ozgur Turetken, John Darcy and David Croson, " managing email overload: solution and future challenges", IEEE computer society Feb 2007.

[6] Lotus, IBM “A lotus Development corporation strategic white paper" January 1998.

[7] Jayanthi Ranjan and Saani Khalil, "Application Of Knowledge Management In Management Education: A Conceptual Framework", Journal of Theoretical and Applied Information Technology 2007.

[8] A Lotus Development Corporation White Paper, "Lotus and IBM Knowledge Management Strategy", Copyright 2010 Lotus Development Corporation.

[9] Robert Peterson, “ artificial intelligence”, 2007.

[10] J. Han and M. Kamber, "data mining concept and technique", Morgan kaufmamm publication 2000.

[11] http://www.knowledge-management-tools.net

[12] http://datawarehouse4u.info/

[13] http://www.jfsowa.com/pubs/semnet.htm 